\title{
Research on Talent Introduction and Cultivation Strategy of Film and Television Industry in New Era
}

\author{
Haochen Qiu \\ Ningbo Red Eagle College, School Party Committee Propaganda Department, Ningbo 315100, China
}

Keywords: new era; film and television; talent introduction; training strategy

\begin{abstract}
Media convergence is a trend in the development of contemporary communications, digital and network technology in highly developed to provide a solid material foundation, to adapt to this trend in the development of the industry needing a large number of professional talents, it has gone abroad in front, and talent cultivation in colleges and universities is relatively lag due to various reasons. Therefore, it is required to keep up with the tide of world higher education development, to adapt to changes in media convergence environment, act as the media communication function, and cultivate media professionals with media convergence thinking, consciousness and innovative ability. In view of this, it is very important to explore the countermeasures of film and television talent cultivation in the background of media convergence based on digital and network platforms.
\end{abstract}

\section{Introduction}

From the end of the century to the beginning of this century, a series of profound changes have taken place in both domestic and international film and television programs. Film and television globalization process is accelerated, China gradually become an important part in the film and television system of globalization. Talent is the most precious resource, how to cultivate, attract and use a good man is currently a major strategic task. Along with the film and television system reform in our country, especially after joining the world trade organization, some foreign Banks have set up institutions in our country, film and television increasingly fierce competition in international economy. This kind of competition is the competition of talented person, national quality competition after all. As an important part of the macro economy, film and television has become the forerunner of the development of the comprehensive national strength of the modern country, and is in a very important position in the national economy. How to train modern film and television talents, and realize the development trend of film and television talent marketization and internationalization has become an irresistible trend. Therefore, the cultivation of a large number of high-level, high-quality, high-level film and television talents has become an urgent and urgent task for the film and television departments.

The value of employees is the increasing function of training information. Only when the enterprise has all the information of general training, including the training content and degree, can the employees be properly resettled and realize their maximum value. For training enterprises, through the observation and understanding during the training, all information about staff training can be obtained. For external companies, this information is not initially available. Only after the employment relationship is started, the enterprise can understand the employees gradually through the investigation of the employee's performance. With the increase of the study period, enterprises are getting more and more information, and the value of employees is gradually increasing. Enterprise employees are trained and training level of the most effective way is to arrange it in need of training post, but in order to avoid the matching error will not be trained on the position of employees to the need to be trained and decreased the risk of performance for productivity or even negative, enterprises will be more willing to its arrangement without training posts. This method is inefficient and requires a long time and a lot of expenses, and the value of employees in external enterprises is lower than that of training enterprises. On the other hand, the trained staff is not willing to accept the 
position arrangement provided by external enterprises in the face of long time of grinding and low efficiency. The above two reasons restrict the flow of employees between enterprises, which ensures the effectiveness of the training investment to a certain extent.

\section{Talent Introduction and Cultivation Strategy of Film and Television Industry in New Era}

First of all, it needs to be explained that the film and television talent mentioned here mainly refers to the talent of broadcasting, film and television directing talents, broadcasting and hosting talents, film and television engineering talents and media operation and management talents. At present, more than 500 colleges and universities in our country have specialized in radio, television, film and television broadcasting or radio, television, film and television, and train all kinds of professionals needed in the industry. From the compilation, guidance, performance, photography, recording, beauty, chemistry, clothing and channel of the film and TV series, it is available for the production, compilation and broadcasting of radio and television programs, as well as the cultivation of film and television engineering talents. These professionals training task is mainly composed of three types of colleges and universities in the bear, is a professional colleges and universities based on the existing function strictly according to the professional requirements of the radio, film and television industry to train various kinds of specialized personnel, technical personnel and marketing management talent; Second, comprehensive universities rely on the abundant subject support and the deep cultural inside information according to the comprehensive quality training mode can meet the need of radio, film and television industry of "wide caliber" talent; Third, various universities rely on their own discipline advantages and characteristics to cultivate the composite applied talents. Over the years, through the efforts of these institutions, the trained professionals can basically meet the needs of the industry and contribute to the development of China's radio and television industry.

The media always expect students from institutions of higher learning to be able to come in handy. The current education of undergraduate level is the students' cultural knowledge reserves and a basic theory of case, and film and television institutions to the requirement of students' professional skills and practical ability is high. This is an obvious for without, etc. Therefore, the objective of the undergraduate level is to cultivate the practical talents with solid foundation, strong practical ability, professional spirit and independent learning ability. In this regard, many universities have already begun to try. Such as Tsinghua University, school of journalism \&communication, since 2004, overhaul the undergraduate teaching plan, established the social science knowledge as the superiority of the tomb. Cultivate and enhance students "radio and television playwright-director vigilant and" editorial' ability. Of course, the cultivation of students' employability and way of thinking is equally important in the study of theory and professional skills. Undergraduate should note, emphasizing the cultivation of independent learning ability, make them master skills "coco", enhance adaptability and transformation of society and the new knowledge ability. Make the film and television professional graduate student competition media presence and other professional jobs when have comparative advantage. In the face of the new trend of the industry media emergence of colleges and universities cultivating talents of radio, film and television, it is easy to fall into a myth, that is, think that as long as it is in, weaving, sowing or culture and pay equal attention to, or the general and special skills training will be able to cater to the needs of the trend of media convergence. This is what we call compound culture. It should be said that adopts the model of the cultivated talents to some extent, although can meet the industry demands for versatile talents, however, that only is a versatile medium in the field of business, rather than a true "convergence" in the sense of versatile medium. Therefore, under the media integration trend, the industry of radio, film and television talent requirement is that requires them to have more media creation, media operation and more knowledge and skills of the operation of the media and with thought and the idea of multimedia integration. This is the so-called integrated practical talent through multi-media learning.

Above is only for radio, film and television of the fusion of media technology level of the talent training scheme design, if you want to come up from structural thinking and solve the problem, we have to stand in the height of the professional construction to organize the implementation of the film 
and television "melting media" the concept of education, that is, according to media convergence concept construction broadcasting movie television playwright-director, movie and TV broadcasting and hosting art and engineering technology and the media business and management professional, and around the course system and implementing details of the talent training scheme, explore effective blending of practical talent cultivation model, focus on cultivating good media literacy and media integration idea and consciousness, familiar with all kinds of media operation procedures, with many media knowledge and skills, and knowledge of specialized personnel in the media business. That is to say, in a professional engaged in radio, film and television media education in colleges and universities, should form and form to radio and television playwright-director, broadcasting and hosting art, image engineering, new media technology, media operation and management as the main stem of professional structure, and penetrate to each other, rely on each other closely around fusion model of radio, film and television talents training target, to cultivate the good media literacy and media integration idea and consciousness, familiar with all kinds of media operation procedures, with many media knowledge and skills, and knowledge of media management business for the specification, so as to highlight the professional integration of educational benefit, and to maximize the satisfaction of the radio, film and television professionals and conform to the degree of the industry requirements.

Under the new situation, the traditional closed school-based training mode is not feasible, so as to emancipate the mind as soon as possible, and integrate with the industry, so as to keep the teaching pace with The Times. Foreign colleges and universities in cooperation with the industry has a more mature experience, in the United States, many well-known production companies are willing to cooperate with professional colleges, lets the student participate in the actual project creation, many established big shots were teaching in professional colleges and universities. Why Disney made today's achievements, is the talent mechanism, it makes the financial institutions, education, game companies, animation companies, such as performance are gathered up and made into a big business.

Film and television industry of many enterprises in our country, hiring difficult under the present situation, take the initiative to colleges and universities into the negotiation for the talent training mode of cooperation, such as the Beijing film academy, the communication university of China, Nanjing art institute and other professional art academy of film and television animation professional made order with enterprise culture, university and enterprise combination education has become a trend. Colleges and universities in our province should also open mentality, in the mode of teaching, change the traditional "classroom teaching" to "field", such as photographing, video-taping, emphasizes the ability of course, can lead the students in the field, in operation for learning and communicating. In the teaching environment, expand the space; get out of the campus to practice in the enterprise. Teachers can be sent to the enterprise to study and training, and the industry's front-line technicians can be invited into the classroom. Teachers lead outstanding students to the enterprise to help enterprises "project", students through "project system" to complete the practice and practical teaching content; can greatly improve the learning enthusiasm and initiative. Students are exposed to the industry through various channels, and they can integrate into the practice of the industry more quickly after graduation. Through communication and cooperation, students can reach the most advanced equipment, technology and experience, and can also increase their ability to communicate and cooperate with others. In terms of teaching content, expand the scope, expand education resources outside the classroom, utilize the network education platform, and share high-quality teaching resources at home and abroad.

In addition, the digital technology era has brought great changes to film and television art, especially in the new media which is developing rapidly. Generally, it covers two modes: first, digitalization of traditional film and television media. For example, mobile multimedia broadcasting and vehicle-mounted mobile TV show the extension and innovation of communication channel in physical space. The second is the fundamental change in the transmission of grass. New media based on Internet and communication networks, including network TV and video, mobile TV, video, IP ding V, etc. At present, our country the development of new media, film and television industry is experiencing a rapid growth, industry convergence, the industrial chain link, increasingly complex, 
increasingly presents the segmentation and the distance, already formed by creation, investment, production, distribution, dissemination, marketing, customer, product development after the complete industry chain, each link between the intersection is thorough, formed the great era characteristics of China's new media, film and television industry. Obviously, the rapid and rapid development of new media has not only brought great challenges to the traditional film and television industry, but also provided more opportunities and broader development space.

On the other hand, the more emphasis is placed on the importance of technology, the more it needs to strengthen the cultivation of students' humanistic cultivation and cultural connotation. In the final analysis, film is an art, and the technical end of the film is the artistic service of the film. Therefore, in the professional film and television education, we should first teach students how to behave and then teach them how to make movies. We should not only impart knowledge and technology to students, but also pay attention to improving students' humanistic quality and cultural connotation. The classic works in the history of Chinese and foreign films are full of vivid characters, vivid story plots, innovative film language, and profound artistic implication. Especially need to point out that the development of Chinese movie is approaching a new climax, how to create more and better, for the world audience favorite Chinese movie need professional film and television education as soon as possible, cultivate a group of proficient in digital technology, good at both the film and television creation and production, and have higher cultural quality and cultural feelings of high-end film and TV professionals.

\section{Summary}

Along with the continuous renewal of digital technology and network technology, media fusion has become inevitable trend of the development of radio, film and television industry, a single skill of employees and a single media has been difficult to support intensive in the field of information communication and fusion of the media huge challenge. The solution to this problem lies in the cultivation and creation of a large number of practical talents adapting to this challenge. For the training function of colleges and universities in this respect ", and explore practical personnel training mode is a priority, we have done is just the beginning, hope sprang out.

\section{References}

[1] Che lanlan. Confusion and opportunity of digital film production [N]. Beijing business daily, 2012-7-20 (A06). (In Chinese)

[2] Luo ying. Research report on talent demand in post-production industry of film and television [[J]. Modern profession education, 2015 (6):64-65. (In Chinese)

[3] The film of the age of digital technology, education [[J]. Modern communication, 2015(3):139-143. (In Chinese)

[4] Jiang xiaoli. Media culture and media research [M]. Chengdu: sichuan university press,2007. (In Chinese)

[5] The enlightenment of education to the training of media talents in China [J]. Degree and graduate student education,2008,(11). (In Chinese)

[6] Zhou anhua. The construction of the core competitiveness of national film and television -- from the media revolution to the direction of education in contemporary film and television [J]. Modern communication,2008,(4). (In Chinese) 